\title{
Updates in ASIA Examination: Anorectal Examination
}

\author{
Evrim COŞKUN ÇELIK \\ Istanbul Physical Medicine and Rehabilitation Training and Research Hospital, Istanbul, Turkey
}

\begin{abstract}
Anorectal exam is a part of the neurological examination developed and standardized the American Spinal Cord Association (ASIA). It evaluates the most caudal roots of the spinal cord, including S3, S4, and S5. Any positive findings on anorectal examination defines incomplete injury.

Keywords: Anorectal examination, spinal cord injury
\end{abstract}

\section{Introduction}

Anorectal examination is a part of neurological examination that is developed by the American Spinal Cord Association (ASIA) and is used for patients with spinal cord injury $(1,2)$. The most caudal roots of the spinal cord, which are S3, S4, and S5, are evaluated with anorectal examination. Any finding of positive anorectal examination reveals that the spinal cord has nerve conduction from the injury level. This suggests incomplete injury of the spinal cord (1-3).

Anal sphincter has three main duties: 1) To store feces in the anorectal region, 2) To perceive sensory/tactile stimuli in the anorectal region and to transmit them to the brain; to enable the brain to recognize gas, fluid, or solid matters, 3) To enable fecal excretion by relaxing anal muscles in consistence with rectal and intestinal peristaltism $(2,3)$.

The internal anal sphincter has a structure of circular organized smooth muscle. Lumbar and sacral region is innervated by sympathetic and parasympathetic nervous systems and controlled by autonomic system. It is active during rest. Expansion in the anorectal tract causes reflex relaxation in the internal anal sphincter (3).

The external anal sphincter is a skeletal muscle. It is under voluntarily or involuntarily control. It is active during rest and is innervated by the pudendal nerve. The somatic sensory (S4-S5) branch of the pudendal nerve receives prick, superficial, and deep anal pressure sensations in the anal and perianal region. The somatic motor branch (S2-3-4) innervates the external anal sphincter (3).

Anorectal examination begins with somatic sensation of the perianal region. Somatic sensation examination of the perianal region (S3 and S4-5 levels) is performed in the supine position. S3 is the posterior midpoint of the gluteal fold, and S4-5 is the area immediately around the anal sphincter. S3 and S4-5 regions must be bilaterally tested with light touch and pricking. The examination results must be recorded as "0: None, 1: Poor, 2: Normal, and NT: Non-tested". The anal channel mucosa should not be tested for light-touch or pricking sensation (1-3).

Before beginning anorectal examination, the patient must be informed regarding anorectal examination. It must be specified that anorectal examination is a part of spinal cord examination, and it can provide information regarding the bowel and bladder functions in the prognosis of injury. It must be explained that anal sensation, deep anal pressure, and muscle contraction of the anal sphincter will be evaluated in the anorectal examination. Female patients must be told that vaginal examination will not be performed (1-3). 
If the patient has anorectal pathology before perineal burn, injury, or laceration, anorectal examination is not performed (3).

\section{Deep Anal Pressure}

Patient is in the lateral position. After wearing gloves, the finger that will be used in the examination is lubricated. The lubricated finger is inserted $2-3 \mathrm{~cm}$ into the anus in adult patients but less in children. Deep anal pressure is tested by applying slight pressure on the anorectal wall with the index finger or by squeezing the anus between the thumb and index finger. Deep anal pressure is evaluated as "yes" or "none" (1-3).

During this examination, repeatable deep anal pressure sensation in the anal region reveals that the patient has sensory incomplete lesion. Because it is determined that patients with light-touch or pricking sensation in S4-5 have incomplete sensation, deep anal pressure examination is not necessary. However, it is recommended for completing the examination form (2).

Deep anal pressure can be the only clinical finding in the sacral region evaluation of spinal cord injury in some patients. Therefore, patients without sharp/blunt differentiation and lighttouch sensation in the perianal region must be carefully examined with regard to deep anal pressure (2). The term of deep anal sensation was changed to the term of deep anal pressure in the revision conducted in 2011 (1).

\section{Voluntary Anal Contraction}

In voluntary anal contraction, the presence of repeatable voluntary contraction of the external anal sphincter around the examiner's finger is evaluated. The patient is asked to squeeze the index finger in the anal channel with the external anal sphincter. For the patient to easily understand our instruction while voluntary anal contraction is being tested, the patient is asked to instruct to the external anal sphincter like "holding the stool during defecation". The result of voluntary anal contraction examination is recorded as "yes" or "no". If there is voluntary anal contraction, the patient is classified as motor incomplete. The differentiation of voluntary anal contraction from reflex anal contraction must be paid attention. If contraction only occurs with the Valsalva maneuver, this reflex can demonstrate contraction, and it should be evaluated as "no" in the voluntary anal contraction examination (1-3).

Some points must be considered while evaluating voluntary anal contraction. Pediatric patients who do not have toilet training may not comply with anal examination. May be the patient does not understand the examination method. Therefore, before the examination, the patient must be informed regarding the examination method, and brief and clear instructions must be simply provided during the procedure. Sedative side effects of drugs used by the patient and cognitive problems that are already available or that occur with injury can prevent the examination to be accurately performed. Moreover, the sensitive personality of the patient may affect the anal examination. Increased intraabdominal pressure or gluteal contractions during examination can be confused with voluntary anal contractions. Voluntary anal contraction can be repeated when instruction is given to the patient. In the examination, when the finger is circularly squeezing, increased gluteal contraction and intraabdominal pressure are experienced on the whole surface of the finger. Anal reflex activities should not be confused with voluntary anal contraction. While anal reflex activities independently occur of the directive during the initial insertion of the finger into the anal channel or with the movement of the finger in the anal channel, voluntary anal contraction can be repeated and occurs with directives (1-3).

Anorectal functions after spinal cord injury can change over time. In the spinal shock period, reflexes can disappear, functions can return, or hyperreflexia can develop. Therefore, anorectal examination is a part of standard ASIA examination. It must be performed with each ASIA examination.

Peer-review: This manuscript was prepared by the invitation of the Editorial Board and its scientific evaluation was carried out by the Editorial Board.

Conflict of Interest: No conflict of interest was declared by the author.

Financial Disclosure: The author declared that this study has received no financial support.

\section{References}

1. Kirshblum SC, Burns SP, Biering-Sorensen F, Donovan W, Graves DE, Jha $A$, et al. International standards for neurological classification of spinal cord injury (Revised 2011). J Spinal Cord Med 2011;34: 535-46. [CrossRef]

2. Gündüz B, Erhan B. Omurga-omurilik yaralanmalarında klinik ve muayene ve sınıflama. In: Hancı M, Erhan B, editors. Omurga ve Omurilik Yaralanmaları. Inter Tıp Yayınevi, Izmir, 2013. p.207-20.

3. In step Anorektal exam modüle 4. Available from: www.asia-spinalinjury.org/elearning. 